\title{
Knowledge from Scientific Expert Testimony without Epistemic Trust
}

\author{
Jon Leefmann ${ }^{1 *+}$ and Steffen Lesle ${ }^{2 *}$ \\ ${ }^{1}$ Center for Applied Philosophy of Science and Key Qualifications, Friedrich-Alexander-Universität \\ Erlangen-Nürnberg, Bismarckstraße 12, D-91054 Erlangen \\ Tel.: +49 91318522325 \\ Mail: jon.leefmann@fau.de \\ ${ }^{2}$ Institute of Philosophy, Friedrich-Alexander-Universität Erlangen-Nürnberg, Bismarckstraße 1, D- \\ 91054 Erlangen \\ Mail: steffen.lesle@fau.de \\ "The authors contributed equally to this paper \\ To be published in Synthese, Preprint Version
}

\begin{abstract}
In this paper we address the question of how it can be possible for a non-expert to acquire justified true belief from expert testimony. We discuss reductionism and epistemic trust as theoretical approaches to answer this question and present a novel solution that avoids major problems of both theoretical options: Performative Expert Testimony (PET). PET draws on a functional account of expertise insofar as it takes the expert's visibility as a good informant capable to satisfy informational needs as equally important as her specific skills and knowledge. We explain how PET generates justification for testimonial belief, which is at once assessable for non-experts and maintains the division of epistemic labor between them and the experts. Thereafter we defend PET against two objections. First, we point out that the non-expert's interest in acquiring widely assertable true beliefs and the expert's interest in maintaining her status as a good informant counterbalances the relativist account of justification at work in PET. Second, we show that with regard to the interests at work in testimonial exchanges between experts and non-experts, PET yields a better explanation of knowledge-acquisition from expert testimony than externalist accounts of justification such as reliabilism. As our arguments ground in a conception of knowledge, which conceives of belief-justification as a declarative speech act, throughout the rearmost sections of this paper we also indicate to how such a conception is operationalized in PET.
\end{abstract}

\section{Keywords}

Expert knowledge, performative testimony, epistemic justification, assertability, epistemic community

\section{Acknowledgements}

We thank audiences in Dublin (UCD) and Erlangen (FAU) for discussion of earlier drafts of this paper. We especially want to thank Isaac Choi (Yale) and two anonymous reviewers for Synthese for doubts and comments that greatly helped to improve the manuscript. 


\section{Introduction}

One of the most important sources of knowledge for human beings is testimony. Unlike other sources of knowledge like perception, memory or inference, testimony is an eminently social source of knowledge. Typically a speaker tells a piece of information to a hearer, who in turn gets to know the reported information. This kind of knowledge-acquisition is inevitable in the complex social environment which modern epistemic subjects inhabit and which is characterized by a high degree of division of epistemic labor. ${ }^{1}$ A major consequence of the increasing division of epistemic labor in modern societies is the growing demand for professional expertise. Whatever social role one occupies, one will be confronted with decisions one cannot make without reliance on expert opinion: the patient relies on his doctor's diagnosis, the minister relies on advice of experts in political strategy planning, the judge needs the testimony from a forensic expert, and so on. Given this ubiquity of reliance on expert knowledge, it might seem odd to claim that most beliefs non-experts ${ }^{2}$ acquire from expert testimony do not qualify as knowledge. Yet given the orthodox conception of knowledge as justified true belief this claim seems warranted: How can it ever be possible for the non-expert, who is not in a position to make a reliable judgement about the reasons counting in favor or against the expert's belief, to be justified in obtaining belief from expert testimony?

In order to specify the conditions under which this question arises, it will be necessary to say more about the particular epistemic asymmetry involved in expert testimony. Therefore the starting point of our investigation will be the claim that the specific epistemic asymmetry in expert testimony arises by virtue of the special properties of expert knowledge, which must be characterized by both, esotericism and a specific social function.

Considering the first characteristic, it should count as a rather uncontested claim, that being an expert in a certain domain of knowledge is a relational property. A necessary but not sufficient condition for being an expert in a domain of knowledge D is that one has significantly more true beliefs about phenomena in D or is significantly more skilled to form

\footnotetext{
${ }^{1}$ If it is impossible that everybody knows everything of importance, epistemic labor must be divided between the members of a society in order to satisfy all the epistemic needs of its members. The division of epistemic labor is, hence, a necessary condition for the distinction between experts and non-experts. These roles could not exist in a society, which demanded that everybody would satisfy their epistemic needs on its own.

${ }^{2}$ We prefer the term "non-expert" to the term "layperson" because it carries much less pejorative connotations and better represents the relational character of the statuses "non-expert" and "expert".
} 
true beliefs about those phenomena than an otherwise comparable person. ${ }^{3}$ The relationality of this property is mirrored by the social processes determining the acquaintance of expertise: Only by a constant contact and collaboration with the expert community can the specific knowledge and skill be acquired. ${ }^{4}$ Expertise consists of knowledge, which is only accessible for persons being similarly educated and as such it is esoteric.

Considering the second characteristic expert knowledge can only be ascribed to persons who are expected to be good informants in their specific domain of knowledge. Being recognized as a good informant is crucial, for I may be a person in possession of a lot of skills or justified, true beliefs but if these skills and beliefs are considered of no relevance to anybody else but me and if I make no use of them whatsoever, no one could ever ascribe an expert status to me. One can only fulfil the social role of being an expert if one is regarded by some of one's fellow experts or non-experts as a person who is in the possession of the knowledge or skill they need. Therefore being visible and approachable as a good informant is inevitable not only for being an expert but for the division of epistemic labor to have any practical consequences. This is not to say that being able to function as a good informant for everybody is a necessary condition for being an expert. Obviously there are many experts who are unable to explain their beliefs to non-expert recipients and do not function as good informants for these recipients. However, being a good informant for somebody - and this somebody might also be another expert or an epistemic peer - is a necessary condition for being an expert. ${ }^{5}$ These two conditions for being an expert, the possession of esoteric knowledge or skill (i.e.

\footnotetext{
${ }^{3}$ Note that this description of expertise is compatible with different definitions of ,truth“. Note further that we are aware of the different kinds of knowledge, which are covered by the term expertise. One can be an expert in virtue of having a great amount of propositional knowledge, but one might as well be an expert in virtue of possessing very good skills and know-how. In this paper we are primarily concerned with scientific expertise, which includes a great amount of propositional knowledge as well as practical know-how about research methodology and the norms of proper research practice. As the context of our investigation is testimonial knowledge, we focus only on the propositional knowledge involved in scientific expertise.

${ }^{4}$ This is important, because expertise is characterized by a great amount of tacit knowledge, which can only be obtained through immersion in an expert community (cf. Collins and Evans 2007).

${ }^{5}$ Note that it is not "expertise", but the notion of "expert" that is defined by this condition. As an anonymous reviewer rightly remarked the audience-relativity of the expert-status involved in this notion implies that some experts could be better positioned to function as good informants for certain non-expert audiences than other experts. While we see why this would be problematic as an implication for the notion of "expertise", we do not see in what way this could be problematic for the notion of an "expert". As long as one (objectively) possesses expertise in a certain domain of knowledge one can already be an expert by virtue of being a good informant relative to a very small and specific audience; in principle a one-person-audience would suffice. Even though being a good informant relative to larger and more diverse audiences would no doubt strengthen one's expertstatus or - as one might want to put it - one's epistemic authority there is no threshold greater than 1 with regard to the size of the audience.
} 
expertise) and someone else's recognition as a good informant, pose problems for the acquisition of knowledge from expert testimony by non-experts.

In contrast to every-day-like testimony (i.e. asking a stranger for the time, receiving information from reading a newspaper) esoteric expert-testimony confronts non-experts with a special kind of asymmetry between themselves and the speaker. This asymmetry exists in virtue of the expert's exclusive access to a domain of knowledge (viz. her domain of expertise). As an expert the speaker is not just temporarily or spatially situated differently than the recipient, she also possesses epistemically relevant experiences and skills which give her further advantage. Because of this, dependence on expert testimony poses an advanced epistemic problem for the recipient. How can the recipient come to know from expert testimony if he has no experience with the domain of knowledge in question and, hence, cannot tell if the received information is true?

Besides this, recognizing experts can be problematic. For it may easily happen that nonexperts mistake epistemically irrelevant properties as indicators for expertise. If a non-expert takes someone as a good informant in an esoteric domain of knowledge who does not possess any knowledge in this domain their ascription of expertise is obviously wrong. The properties a non-expert takes to indicate the expert's expertise must be related to the expert's actual epistemic properties. Hence, for knowledge acquisition from expert testimony to be successful the non-expert is not only required to be in a position to gain justification for a testified belief which he is unable to epistemically assess. He is also required to be able to reliably recognize who is a good informant with respect to his informational needs.

Traditional formulations of the problem of knowledge from expert testimony have set the problem of epistemic justification center stage. What justifies the belief a non-expert acquires from expert testimony as knowledge ${ }^{6}$ The debate on the epistemology of testimony has brought about several general solutions to this pressing problem (cf. section 2). These solutions, however, very often neglected the specific context of expert testimony and

\footnotetext{
${ }^{6}$ One could object that this question misrepresents the phenomenon of expert-to-non-expert-communication, because one might think that what non-experts usually want from expert testimony is not knowledge in the sense of justified true belief, but true belief simpliciter. Most of the time non-experts fare quite well with true belief, at least as long as they are not pressed by others to give reasons for their testimonial beliefs. Moreover, even if the non-expert would be pressed by his fellow non-experts, most of the time a simple "a reliable expert told me so" will suffice to calm the doubts. As will become clear in the following pages, our approach to knowledge from expert testimony is able to account for a great variety of contextual justificatory requirements. These include contexts, in which the non-expert can aim at true belief simpliciter, because he already possesses a contextually sufficient justification, as well as many other more interesting contexts, in which an already existing justification ("a reliable expert told me so") will be insufficient to calm his critical audience's doubts. In those latter cases it is always preferable for the non-expert to aim for more than just true belief from expert testimony.
} 
frequently left untouched the social role of the expert as recognizable and reliable informant ${ }^{7}$. Therefore, from section 3 on we will present our solution for this problem which takes these issues into consideration

\section{Evidence or Trust? - Current approaches to the Justification Problem of Expert Testimony}

Since the epistemological debate on testimony as a source of knowledge has been revived in the early 1990s (Coady 1992; Chakrabarti and Matilal 1994) the question of what makes it reasonable for a knowledge interested recipient to accept testimony has been discussed from two general perspectives. In an earlier phase of the debate approaches to knowledge from testimony argued that a recipient's justification for believe in p could only be epistemically adequate if it was based in some kind of evidence for or against the truth of a testified belief. Approaches following Hume emphasized that accepting testimony is reasonable, because one can on experience establish correlations between testimony and truth. According to such reductionist approaches belief in expert testimony would be justified through independent evidence for the claims made by the speaker. As a consequence, reductionist theories do not see testimony as a generic source of knowledge. Opposing non-reductionist approaches associated with the work of Thomas Reid, however argued that testimony is itself evidence for the truth. So as long as an recipient has no concurring evidence against the truth of a testified belief, it would be a priori justified to belief in testimony. As we will discuss below, both these general evidentialist options raise problems especially with regard to expert testimony.

Theories avoiding many of the pitfalls of both these approaches have spread partly as a reaction to the reductionism-non-reductionism divide since the mid of first decade of the new millennium (Moran 2005; Hinchman 2005; Lackey 2008; Faulkner 2011). Some of these theorists at least partly give up the central role of evidence and propose approaches, in which

\footnotetext{
${ }^{7}$ One might doubt, whether it is actually possible for a non-expert to acquire knowledge from expert testimony in the strict sense of justified, true belief. However our practice of ascribing knowledge strongly opposes this view. Non-experts can have knowledge of the existence of Black Holes or the Higgs Boson without ever being able to directly give reasons for their beliefs, which are independent from (expert) testimony. The semantic of "to know" allows us to say that an interested non-expert not only has a true belief about the existence of Higgs Bosons, but a belief, which can be justified in virtue of being mediated by testimony. Denying the possibility of knowledge from expert testimony leads us directly into Hardwig's trilemma: If it was impossible to gain knowledge from expert testimony, we would either face the problem (a) that much of what we think non-experts know is not actually knowledge due to lack of justificatory evidence, or (b) that it is possible to know without any justificatory evidence, or (c) that the community of expert and non-expert is the bearer of knowledge (Hardwig 1991, p. 699).
} 
the relation between speaker and recipient or concepts of trust and self-trust feature important roles. As we will see, however, their answers often seem to justify the recipient's testimonial belief on non-epistemic reasons.

Before we will suggest our own approach to the justification problem in section 3 we will briefly review some of the theories from both phases of the debate with regard to the justification problem and discuss how well they are suited to explain the acquisition of knowledge from expert testimony.

\section{a. Evidence-based approaches}

Let us start our discussion with a general theoretical approach that gained much of its plausibility from observations about the fundamental conditions of human communication: Non-reductionist theories of testimonial knowledge maintain that recipients of (expert)testimony have an a priori entitlement to trust reported beliefs (Coady 1992; Burge 1993). The main argument for this position is that in order to be transmittable in acts of communication, propositional content needs to be preserved. One cannot understand testimony of one's counterpart, if there were no stable relation of reference between the words and sentences uttered by a speaker and the propositions to which these utterances refer. However, non-reductionists are usually very careful, when it comes to licensing general trust in a speaker's testified beliefs. To avoid giving credulity a carte blanche non-reductionism demands that critical recipients of testimony should look for negative evidence, which could defeat the trusted beliefs. Non-reductionism requires ruling out evidence that would debunk or undermine the truth of testimonial belief. In this perspective the non-expert would be justified to trust anything the expert testifies, as long as he cannot come up with convincing evidence that speaks against the truth of the expert's testimony.

Given the special situation of lay-expert-communication it seems obvious why nonreductionism should be considered a non-starter for a solution to the justification problem. It is one of the biggest problems with expert-testimony that there is hardly any shared language of expert and non-expert in the expert's domain of expertise. If an expert testifies, a nonexpert has no sufficient background knowledge to make any assessments concerning the defeating conditions ${ }^{8}$ for this kind of testimony. If one is not even able to understand the

\footnotetext{
${ }^{8}$ Defeating conditions are conditions under which a testified belief is wrong. For example, the sun standing in the zenith is a defeating condition for the testified belief that it is $5 \mathrm{pm}$ now.
} 
uttered proposition, it seems impossible to be sensitive for appropriate defeaters. Hence, in order to acquire adequate reasons to assess the truth of expert testimony, the non-reductionist would need to presuppose that the non-expert is on the same epistemic level as the expert and, hence, to deny the distinction between non-expert and expert. Because of this, nonreductionism is not a position to solve the problem of expert testimony.

Contrary to these positions a less skeptical approach has been explored by Alvin Goldman (Goldman 1999, 2001). Goldman is less concerned with a priori entitlements to trust experts, but focuses on the non-expert's possibilities to identify experts and to actively access their trustworthiness. Goldman's approach seems promising, for it acknowledges that in the case of expert testimony defeating conditions are never obvious for non-experts and thus avoids a central flaw of non-reductionism. Due to their epistemic shortcomings non-experts have no possibility to show that a testified expert opinion is wrong. What they might have, however, is a possibility to assess the reliability of expert testimony.

Goldman's solution to the - as he calls it - novice/expert-problem is to regard it from a temporal point of view (Goldman 1999, p.268). He thinks non-experts could recognize whether someone actually is an authoritative expert by confirming the truth of the expert's assertions after they have been uttered. A non-expert in medicine for instance may not know whether the diagnosis presented to him by a medical doctor is accurate, but he might - in principle - confirm its truth by looking for independent evidence. The easiest (though perhaps not the most recommendable) way for the non-expert to acquire independent evidence would be to accept the doctor's diagnosis and therapeutic recommendation, and to see whether his medical condition reacts to the treatment as predicted. This way, one might say that after the condition has improved the non-expert somehow comes to "know" what the doctor knew. For only after the treatment he has evidence for his belief that he was suffering from a certain disease and for his belief that the prescribed treatment is (somehow) related to his betterment. ${ }^{9}$ However, such confirmations are obviously insufficient to constitute knowledge from expert testimony. This is not only because hardly any scientifically educated person would accept the improvement of a medical condition alone as a sufficient evidence for a doctor's accurate diagnosis and appropriate treatment (the doctor could have simply made a lucky guess or her diagnosis and treatment might even have been wrong when the improvement of the patient's

\footnotetext{
${ }^{9}$ Goldman (2001) provides a similar example for the case of esoteric astronomical knowledge becoming exoteric over time. A non-expert cannot confirm an astronomer's prediction of a future solar eclipse but he can easily confirm the astronomer's prediction on the day the eclipse happens.
} 
medical condition occurred independent of the medical treatment). More importantly this strategy misinterprets what is actually at stake in the acquisition of knowledge. In interacting with experts non-experts have an interest to know (as opposed to only trust) the expert's opinion. As knowledge seeking humans we want not only accidentally true beliefs but sustainable true beliefs. This is first, because having stable and sustainable true beliefs is cognitively more efficient than just having true beliefs. Rethinking what counts in favor of a belief each time one forms the belief, requires more cognitive resources than knowing why one holds as true the belief in question. Second, sustainable true belief makes one a more reliable informant for others and enables oneself to give advice to others and to convince them to share one's belief, viz. it enables a person to justify his beliefs by giving plausible reasons to others. These are eminent practical interests connected to knowledge as opposed to merely true belief. A non-expert, who comes to "know" what the expert has testified by simply waiting for the expert's prediction to come true, does not gain knowledge in this required sense.

This view of Goldman's confirmation account, however, is obviously too simple, as there are, indeed, further possibilities for independent verification. The non-expert, instead of waiting for conditions to accidentally confirm his belief, may, for instance, actively consult an additional doctor or a diagnostic manual for further evidence. Nevertheless, in both cases finding this kind of independent verification can be quite demanding. ${ }^{10}$ For even if the nonexpert consults an additional doctor or an "uncontestedly reliable" (Goldman 1999, p.269) diagnostic manual, he will probably face further problems: In case of the uncontestedly reliable diagnostic manual, the non-expert will lack the skill to understand and access most of the listed diagnostic criteria. And also consulting an additional expert may lead to further complications. If the two experts disagree, the non-expert would have to decide, which one of the two expert's he should trust without being able to epistemically evaluate either of the two competing assertions; a problem Goldman has discussed more lengthy as the novice/2-expert problem (Goldman 2001). The criteria Goldman uses in his sketch to solve this problem - viz. comparing (a) the two experts' argumentative performances, (b) their credentials or the number of agreeing fellow experts respectively, (c) evidence about their potential biases and

\footnotetext{
${ }^{10}$ This is probably the reason why Goldman only discusses much less problematic examples such as geographical or mechanical knowledge (Goldman 1999). A person who is told the way to the town hall or the cause for the malfunctioning of his air-conditioner can simply verify the truth of such propositions by following the described pathway or by checking whether the air-conditioner works after he repaired it according to the expert's instructions.
} 
competing interests, and (d) their track record - have been widely discussed in the literature and often found wanting especially by authors considering non-ideal, real world circumstances (Brewer 2006; Coady 2006; Almassi 2012; Martini 2014). These criteria are often found to be insufficient, basically because the relevant information to assess them is often not easily available to non-experts or because the search for the suggested independent evidence might overburden the non-expert (Guerrero 2017).

However, in many contexts Goldman's criteria to rate experts for their trustworthiness might still work quite well. One should stress, therefore, that many arguments against Goldman's confirmation approach rely on the supposition of a non-ideal context in which relevant information is difficult to access for non-experts and in which experts fall prey to many of their biases and extra-scientific interests. But even if there was a suitable solution which allowed for the identification of reliable experts even in non-ideal contexts, there is a still more fundamental argument against this and similar views: Engaging the non-expert to actively look for sufficient and relevant evidence to confirm the expert's testimony tends to reduce the very idea of the division of epistemic labor to absurdity. If the non-expert would have to engage most of his epistemic resources to search for evidence for holding an expert's belief as true, he might as well have invested these resources to become an expert himself. ${ }^{11}$ In treating knowledge from expert testimony as something, which needs to be independently confirmed, reductionism leaves us with the primary dilemma of knowledge from expert testimony: Either the non-expert's epistemic resources are structurally insufficient to attain justified true belief, or we need to grant that the non-expert can "know" on blind trust, viz. without adequate justification.

\section{b. Trust-based approaches}

While evidentialist theories focus entirely on epistemic reasons for testimonial belief, a significant number of alternative approaches make reference to the importance of trust (or distrust) as attitudes shaping the moral and epistemic relationships between experts and nonexperts. One of the most notable formulations of the problem of justification with respect to

\footnotetext{
${ }^{11}$ In defending reductionism, one might want to insist that it is not necessary to demand all the epistemic work of expert-assessment to be done by single non-expert. A reliable, easily accessible, and regularly updated expert registry might bundle the experiences of a whole community of non-experts. Still, this does not circumvent the problem, but only pushes it to an institutional level. How is a single non-expert to obtain enough independent evidence to decide whether or not to trust the registry's collective testimony?
} 
scientific experts is John Hardwig's plea for the inevitability of epistemic trust (Hardwig 1985). According to Hardwig a non-expert is not only unable to have beliefs in the expert's domain of expertise, he is also unable to form beliefs about the expert's reasons for holding these beliefs. The non-expert lacks the ability to decide on his own whether the expert's belief is true or false and whether the expert's cited reasons in support of this belief are reasonable. But Hardwig's skepticism reaches even further, for a consequence of this view is that it must be impossible for the non-expert to identify experts based on epistemically relevant reasons. Of course, the non-expert may take someone for a medical expert. But this opinion will inevitably be based on judgements about superficial markers for medical expertise, such as for example a doctor's white coat, her use of medical vocabulary, or a habitus typical of medical doctors; thus the inevitability of epistemic trust in experts.

In Hardwig's account epistemic trust in scientific experts is justified by the expert's morally and epistemically trustworthy character (Hardwig 1991), viz. the expert's commitment to the scientific virtues of truthfulness and accuracy. But as the moral and epistemic trustworthiness is a personal property (and not a property of the testified proposition p), Hardwig conceives of the justification for belief in expert testimony as defying the non-expert's control. That is: belief from expert testimony counts as knowledge only, if the expert is in fact reliable and trustworthy.

Hardwig's work is meritorious, because it turned the focus in the debate about testimonial knowledge on epistemic trust as a moral concept. ${ }^{12}$ However, besides the insistence on the inevitability of epistemic trust and the argument for a better research ethics education to allow for trustworthy experts (Hardwig 1991), he remained silent on the question how exactly the non-expert's personal trust in the expert could justify testimonial belief. As we will see, this is because in his and many other accounts of knowledge on trust the relationship between nonexpert and expert (or recipient and speaker respectively) is grounded in moral attitudes that lack epistemic significance.

This point can be illustrated in several more recent approaches, which aim (amongst other things) to explain the rationality of epistemic trust, by showing how the attitudes involved in

\footnotetext{
${ }^{12}$ As a moral concept trust is often regarded as involving an expectation of the trusted person's good will (Baier 1986) or commitment (Hawley 2014) towards the trustee and is opposed to thinner notions of "trust". Thinner notions require only the expectation of a trusted person's rationality and self-interest (Hardin 2002). These descriptions of "trust-relationships" are often also addressed as "mere reliance". For an overview on the more recent debates on trust in ethics, epistemology and social philosophy see (Faulkner and Simpson 2017).
} 
the relationship between non-expert and expert can warrant the non-expert to think of an expert as morally and epistemically trustworthy.

For an example consider Karen Frost-Arnold's account of trust as taking the assumption that the trusted person will act as expected as a premise in one's practical reasoning (Frost-Arnold 2014). In trusting another person to $\varphi$, Frost-Arnold argues, one makes plans based on the assumption that the person will $\varphi$ and making such plans can either amount to believing that someone will $\varphi$ or to simply accepting that someone will $\varphi$. On this account one can trust someone, without believing that the person will act as expected. This is due to the inclusion of acceptance as a cognitive attitude involved in trusting and allows this account to explain various phenomena in which persons choose to trust for practical reasons. ${ }^{13}$ One of these phenomena of interest is coping trust. Coping trust is trust in someone in order to simplify one's reasoning or to avoid anxiety. For example, the non-expert could have coping trust in the expert because the assumption that the expert is trustworthy helps him to avoid the cognitive burden of finding out whether $\mathrm{p}$ by himself or to avoid a doxastic paralysis that can result from excessive attention to one's epistemic vulnerability due to one's ignorance of $p$. Such coping trust can often be rational from a pragmatic point of view and as long as the costs of acquiring false belief from expert testimony are likely to be low and as long as there is no overwhelming evidence against the expert's trustworthiness, it can be pragmatically rational for the non-expert to trust the expert's testimony that $\mathrm{p} .{ }^{14}$ However, pragmatic reasons for believing an expert's testimony are insufficient as a justification for believing that $\mathrm{p}$. Acquisition of knowledge as opposed to merely true belief requires epistemic reasons, e.g. reasons for the truth of $\mathrm{p}$. And though adopting a trusting attitude may in certain circumstances pragmatically be rational and even conducive of true belief, coping trust does not provide reasons for the truth of $\mathrm{p}^{15}$

\footnotetext{
${ }^{13}$ In what way it is possible to choose to trust is object to an extensive debate within the philosophy of trust (Holton 1994; Baier 1986). Theories taking belief to be constitutive of trust typically face the problem of doxastic voluntarism (Hieronymi 2008a).

${ }^{14}$ Qualified in this way it would for example be pragmatically rational for a patient to adopt an attitude of coping trust regarding his family doctor's diagnosis of a severe cold but not regarding his family doctor's diagnosis of, say, a rare auto-immune disease. However, even if the risk of acquiring a wrong belief in the former case would be extremely low and the costs of acting on false belief manageable for the non-expert, her reasons for her belief in the doctor's testimony would be entirely pragmatic.

${ }^{15}$ The focus on an agent's pragmatic reasons to trust is also revealed in Frost-Arnold's discussions of moral trust in science (Frost-Arnold 2013). To explain the practice of scientific collaboration despite the dangers of coercive authorship and ineffective institutional detection and sanctioning of scientific misconduct she makes a case for the prevalence of moral trust in science as opposed to mere reliance between researchers. However, while all this is convincing as an argument for the diffusiveness of moral trust in science it does not add much to the question of how trust in a scientist's testimony can justify the non-expert's belief that $\mathrm{p}$ as knowledge.
} 
A way to avoid this lack of epistemic reasons is suggested in Paul Faulkner trust theory of testimony (Faulkner 2007, 2011). Faulkner's account rests on the distinction between two forms of trust - predictive trust and affective trust - of which only the latter adequately explains the rationality of trust in a testified belief $p .{ }^{16}$ On this account a recipient epistemically trusts a speaker in the predictive sense, if he knowingly depends on the speaker's truthful testimony and expects that the speaker will testify truthfully. In this case the recipient's reasons to believe what is testified are predictive reasons, i.e. reasons that justify the expectation that the speaker will truthfully testify. Thus, the justification of predictive trust depends on the recipient's evidence for the truth of his prediction. Predictive trust is the kind of "calculated" or non-moral trust that has its place also in evidentialist accounts of testimonial knowledge. Therefore, affective trust features as the more interesting variety in Faulkner's theory of testimony. Affective trust involves the recipient's expectation that the speaker will take his dependence on the truth of her word as a motivating reason to testify truthfully. This variety of trust is affective in the sense that expecting the speaker to be motivated that way need not involve the recipient's belief that the speaker will actually be so motivated. One can decide to trust a speaker in order to build (or keep) a trusting relationship, and in these cases one is not required to believe (or to predict) that the speaker will be trustworthy (in fact one may even believe the contrary). ${ }^{17}$ So in many cases of affective trust one simply presumes that the trust invested in the speaker will be a reason for her to be trustworthy. Of course there are limitations to making such a presumption and, hence, cases in which affective trust would be unreasonable: for instance, if the recipient has insufficient reasons to expect the speaker to be aware of his dependence on her testimony or if the recipient has insufficient reasons to believe that the speaker will be motivated by her awareness of this dependence. However, as far as adopting the attitude of affective trust is reasonable believing $\mathrm{p}$ on this variety of trust can be justified. This is, Faulkner argues, because the speaker's trustworthiness is a direct epistemic reason to believe her testimony that p. And as the speaker's trustworthiness is a result of the affective trust the recipient has invested in the speaker, his epistemic reason for believing $\mathrm{p}$ is in a certain sense generated

\footnotetext{
${ }^{16}$ In the emphasis of trust as a (partly) affective attitude Forst-Arnold's considerations significantly overlap with Faulkner's. However, on Faulkner's account the distinction between predictive trust and affective trust is similar but not congruent with the distinction between reliance and trust (Baier 1986) on which Frost-Arnolds theory is based. Predictively trusting involves the recipient's willingness to depend, which is expressed in his belief that the speaker will speak truthfully. In reliance the recipient lacks this belief.

${ }^{17}$ For discussions about whether trust is fundamentally based in belief or in affective attitudes and the question whether it is possible to decide to trust see also (Holton 1994; Jones 1996; Lahno 2001; Faulkner 2007, 2011, 2014; Kappel 2014; Frost-Arnold 2014).
} 
through his trusting. One might say that affective trust is a way for the recipient to generate the speaker's trustworthiness which provides an internalist justification for accepting the speaker's testimony. This theory would, however, be flawed if it was not supplemented by the requirement, that also the speaker must be justified in his belief that $\mathrm{p}$. The recipient's justification for believing that $\mathrm{p}$ derives from the speaker's trustworthiness and from the speaker being in fact justified to belief that $\mathrm{p}$. And this is a particularly interesting result from the perspective of expert testimony: For the recipient (or non-expert) can have knowledge that $\mathrm{p}$ despite not knowing the speaker's (or expert's) epistemic reasons for $\mathrm{p}$.

While this is the result one needs to explain the possibility of knowledge from expert testimony, this account has still an important limitation: It works only in contexts in which non-experts form an epistemic community that shares the conviction that there are reasons to invest affective trust in the expert. As soon as someone in this community dares to doubt the expert's trustworthiness or the expert's belief that $\mathrm{p}$ it seems, however, that an important part of the non-experts' justification for the testimonial belief that $\mathrm{p}$ gets lost. This is because on this model an individual non-expert has epistemic reasons for $\mathrm{p}$ only by virtue of having personally invested trust in the expert. And as a consequence he is unable to justify his testimonial belief that $\mathrm{p}$, if someone doubts the expert's trustworthiness.

This is a problem, which is also faced by other accounts such as for example Thorsten Wilholt's theory of epistemic trust in science (Wilholt 2013). Wilholt shares Hardwig's view that the operation of science as a collective epistemic enterprise must inevitably involve epistemic trust in the research reported by fellow scientists. According to Wilholt given the collaborative nature of science every scientist must assume that their fellow scientist's epistemic endeavors are appropriately geared towards the truth and must work this assumption into his own research projects. On the one hand this assumption is inevitable, because there are no objective standards for balancing inductive risks (viz. the risk to falsely accept and wrong hypothesis vs. the risk to falsely discard a right hypothesis) in the research process. But on the other hand it can also be considered as justified because there are conventional standards for balancing such risks in different research fields. ${ }^{18}$ Assuming objective methodological standards one could model collaboration in science on the assumption of mutual reliability. The establishment of conventional standards, however,

\footnotetext{
${ }^{18}$ According to Wilholt conventional methodological standards of a research field need not be explicitly taught or written down in documents. Many of these standards are implicit and revealed only when someone's research is found to have violated a particular standard.
} 
involves itself complex trade-offs between different kinds of inductive risks. And such tradeoffs cannot be made without a value based evaluation of the costs and benefits of correct results relative to incorrect results, viz. without evaluating the consequences of making the errors of either falsely accepting a wrong hypothesis or of falsely rejecting a correct one. Hence, Wilholt argues, the division of epistemic labor in the sciences requires also reliance that researchers adhering to a conventional methodological standard have the appropriate evaluative attitude towards the practical consequences of their research. It is this kind of reliance in the evaluative attitudes of one's fellow scientists that Wilholt terms "epistemic trust". So on his account A epistemically trusts the results reported by a fellow scientist B, if A assumes that B's evaluation of the benefits of correct results relative to the costs of incorrect results are approximately the same as those A herself would have made under the same circumstances. Hence, A's trust in the truth of the reported result $p$ is justified by virtue of her assumption that $\mathrm{B}$ shares her own evaluative attitude towards the methodological standards applied.

This, however, has two consequences we already named as problematic. First, as with FrostArnold's account the reason that justifies A's epistemic trust is a non-epistemic one for the reason that justifies A's trust (as opposed to A's mere reliance) in B's testimony is A's belief about B's evaluative attitude. Second, as in Faulkner's theory A's trust in B is epistemically justified only as long as A and B form a community of (moral) peers. Both these implications are quite understandable given that Wilholt thinks that science as a social enterprise would be underdetermined if truth was its only aim and if it lacked this non-epistemic, evaluative dimension (Wilholt 2013, p.252). However, neither of them applies in the context of testimonial exchanges between non-experts and experts.

As a first summary one could say that all these accounts primarily focus on the non-expert's expectations about the expert's attitudes towards their epistemic dependence and thus provide only indirect resources to account for the non-expert's need for epistemic reasons for $\mathrm{p}$. What they provide is reasons based in pragmatic or evaluative considerations that render trust in another's testimony reasonable. But these reasons derive from structural aspects of the layexpert-relationship. Some accounts of epistemic trust in feminist epistemology (Daukas 2006) and in virtue epistemology (Zagzebski 2012) have, however, put stronger emphasis on the 
recipient's (or non-expert's) self-trust as a condition for acquiring knowledge from testimony. $^{19}$

This emphasis on the epistemic self-trust as a structural criterion for justifying belief on trust appears prominent in a solution to the justification problem laid out more recently in Linda Zagzebski's widely discussed work on epistemic authority (Zagzebski 2012). ${ }^{20}$ Arguing from a virtue epistemological perspective Zagzebski seeks to motivate the claim that it can sometimes be the most epistemically virtuous behavior to believe on authority. In this view, an epistemically virtuous person (or non-expert; NE) has a prima facie reason to believe that $\mathrm{p}$, if he judges that another person (or expert; E), who believes that $\mathrm{p}$, has better epistemic skills and is epistemically more virtuous than him. Zagzebski models E as an epistemic authority for NE on the conditions that

1) E's judgement is taken by NE as authoritative independent of the content of E's assertions

2) E's believing that $p$ constitutes a preemptive reason ${ }^{21}$ for $N E$ to believe that $p$

3) E's belief that $p$ was formed in a way that NE would conscientiously believe to deserve emulation, and

4) NE considers it justified to believe that $p$, because he thinks it more likely to form a belief that survives his conscientious self-reflection, if he believes what E believes than if he tried to figure out what to believe by himself (Zagzebski 2012, pp.105).

Transferred to the context of expert testimony this view considers the conditions under which an epistemically virtuous non-expert, whose primary aim is the acquisition of true beliefs would be rationally required to defer to the expert's epistemic authority. This way Zagzebski's theory is centered on the perspective of the inquiring non-expert, as she sees the status as an epistemic authority as relative to the non-expert's judgements of epistemic competence and virtuousness. An expert is an epistemic authority for a non-expert only

\footnotetext{
${ }^{19}$ On Daukas' theory one can be an epistemically trustworthy person only if one is disposed to extend the presumption that a speaker's expression that $p$ is also a reason for the truth of $p$ (i.e. the principle of charity) only to those persons who are epistemically trustworthy as well and to withhold extension if those persons are not. For the context of non-expert-expert-communication this means, that the audience's character traits relevant to her own epistemic trustworthiness guide non-experts in identifying epistemic trustworthy experts. Only if the non-expert is disposed to be epistemically trustworthy himself, he will be able to have accurate beliefs about other persons' epistemic characters and competences and will extend or withdraw the principle of epistemic charity when it is appropriate. So whether a non-expert is disposed to rationally place his epistemic trust finally depends on his own epistemic character traits. It is here where one finds the fundamental similarity with Zagzebski's approach.

${ }^{20}$ For critical discussions of Zagzebski’s view see also (Jäger 2016; Lackey 2016; Dormandy 2017).

${ }^{21}$ A preemptive reason for the belief that $\mathrm{p}$ is a reason "that replaces my other reasons relevant to believing $\mathrm{p}$ and is not simply added to them.” (Zagzebski 2012 p.107).
} 
insofar as the non-expert judges that it is more likely that the expert will figure out the truth with regard to $p$ than he will figure it out by himself. So, given epistemic self-trust - viz. trust in one's own competence to make correct epistemic judgements - the non-expert's judgement that it would be better to trust the expert's epistemic virtuousness than to trust his own epistemic competences, provides a reason to justify his trust in the expert's belief.

This is to say, however, that Zagzebski's approach is based on the precondition that epistemic self-trust is fundamental in all epistemic activities. The basic epistemic attitude is trust that what one takes as indicative of the truth is in fact indicative of the truth. And this presumption has an important implication for Zagzebski: The fundamental form of an epistemic reason is a deliberative, first-personal reason and not a theoretical, third-personal reason. ${ }^{22}$ As a consequence she opts for a form of the so-called "assurance theory" (Moran 2005) as the proper account of testimony (Zagzebski 2012, pp.121). Assurance theories conceive of testimony as itself constituting a normative relationship of responsibility and trust between a speaker and a recipient. Through addressing the non-expert and telling him that $\mathrm{p}$ the expert invites the non-expert to trust him that $\mathrm{p}$ and takes over responsibility for the truth of the nonexpert's belief that $p$. If the non-expert, in turn, accepts this invitation to trust he acknowledges the expert's credibility and gains the right to blame the expert when his trust is betrayed. ${ }^{23}$ In Zagzebski's terms an invitation to trust can be taken as a deliberative, firstpersonal reason by the non-expert, which contingent upon the fact that he judges the expert to

\footnotetext{
${ }^{22}$ Deliberative reasons are subject-dependent epistemic reasons. Like self-trust, many mental states such as trust in others, intuitions, memory or experience can provide reasons to believe that $\mathrm{p}$, which cannot be direct reasons for others to believe that $\mathrm{p}$. Theoretical reasons, instead, are subject-independent and are open as epistemic reasons to everyone. Evidence is a typical third-personal reason. For instance the fact that I have experienced that $p$ may be taken as evidence by others for the truth of $\mathrm{p}$. As such it constitutes as a theoretical reason in favor of p (Zagzebski 2012, pp. 63).

${ }^{23}$ Analyzing testimony as a speech act of telling as opposed to a speech act of asserting, assurance accounts argue that justification for belief in (expert-)testimony is not (primarily) based in the audience's epistemic selftrust but in the epistemic responsibilities of the speaker (Moran 2005; Hinchman 2005; Faulkner 2007; McMyler 2011). In telling a speaker is not simply asserting a proposition, she also represents herself as having reasons for $\mathrm{p}$ that should be good enough for the audience. The speech act of telling signals that the speaker intends to be believed and intends to take responsibility for the truth of his assertion's propositional content. Hence, through the act of telling the speaker assures the audience that $\mathrm{p}$ is true and this assurance entitles the audience to believe that p. For the distinction between the speech acts of "assertion" and "assurance" see also (Lawlor 2013, pp.9).

${ }^{23}$ This way telling constitutes a normative relationship between speaker and audience, in which the audience is invited to trust the speaker and in virtue of this can legitimately hold the speaker responsible should his trust be betrayed and his testimonial belief that $p$ turn out to be false. The audience's justification to belief that $p$ then does not derive from evidence the speaker presents for the truth of $\mathrm{p}$ but directly from the audience's understanding of the speech act of telling.
} 
be an epistemic authority in the sense of conditions $1-4$, would justify his belief in the expert's testimony. $^{24}$

This is an interesting and favorable move, because most "assurance accounts" of testimony do not require epistemic self-trust as a further source of reasons for believing testimony. The advantage for Zagzebski's theory, hence, seems to be that a non-expert's reasons for believing $\mathrm{p}$ do not reduce to moral reasons that derive from the trusting relationship to the expert but also involve epistemic reasons regarding one's own epistemic conscientiousness. Again, however, this is not enough to give the non-expert a direct epistemic reason for $p$. The nonexpert's only quasi-epistemic reason is his own trusted capacity to judge that the expert deserves to be epistemically admired.

Unfortunately there is a general weakness in all these accounts built on assurance and epistemic self-trust: The recipient's knowledge is justified by virtue of structural elements of testimonial exchange (viz. character traits like epistemic trustworthiness, conscientiousness or integrity, properties of speech acts or shared evaluative attitudes). These structural elements are bound to the properties of the persons involved in testimonial exchanges and hence either prevail or not. Whether they prevail or not is, however, very often unknown to the non-expert. That is to say, that the indirect epistemic reasons these accounts at best provide for the truth of p only work in externalist justifications. On these accounts only the pragmatic and moral reasons for trusting the speaker can be known by the recipient - and provide an internalist justification. The challenge for the problem of justification - at least as we see it - is, however, to provide an internalist justification for the testimonial belief that $\mathrm{p}^{25}$

Of course, all this is not to say that trust does not play an important role in our epistemic lives or that trust in experts cannot be rational. In fact all these accounts convincingly show how extensive a role trust features in the epistemic lives of us humans. From the perspective of the problem we investigate in this paper, however, they are insufficient. While they allow to explain how trust enables the acquisition of true belief, they fail to explain how trust enables knowledge in the sense of an adequately justified true belief. And while they work as explanations of true belief acquisition as long as non-expert and expert are willing to uphold a trusting relationship they get into trouble when the mutual attitudes of non-experts and experts

\footnotetext{
${ }^{24}$ As Zagzebski is not primarily concerned with expert testimony but with a general account of testimony an invitation to trust can also constitute a deliberative, first-personal reason to believe a speaker, if the audience does not consider the speaker to be an authority. In general it suffices for an invitation to trust to constitute a reason of this kind, if the audience judges the speaker to be at least as epistemically conscientious as himself. ${ }^{25}$ For the reasons why we think an internalist justification would be desirable see section 7 of this paper.
} 
towards one another cool down. As soon as a non-expert adopts a more aloof attitude and begins to doubt the expert's testimony, trust-based explanations have to face their limitations. The upshot of this discussion is, hence, that neither epistemic trust nor confirming or debunking evidence are plausible candidates for a solution to the justification problem of expert testimony. Therefore, we think a novel approach is called for. Other than the approaches discussed so far, the solution to the justification problem we will explain and defend on the following pages conceives of justification as a shared social practice of experts and non-experts. Besides pragmatically trusting the expert that her testified belief holds true or looking for independent evidence for or against this belief, we think there is a third option for the non-expert: It is only through a reasonable and truth-conducive confirmation of the testifier's expert status that a non-expert can acquire reasons for belief in expert testimony.

\section{Performative Expert Testimony}

Our approach to the justification problem of expert testimony is called "Performative Expert Testimony" (PET). PET is "performative", because it requires the expert to make practical use of her expertise with regard to the non-expert's questions and doubts about the truth of her testified belief. Furthermore PET is "performative" in the sense that the non-expert's justification for believing the expert's testimony is constructed through the interaction of expert and non-expert. Even though we do not agree with Hardwig's plea for the inevitability of epistemic trust, one could say that it was Hardwig's third option in the trilemma ${ }^{26}$, which set a first step to paving a way for PET. Hardwig seems to suggest, one should give up on the idea that knowledge is based in an individual's belief and rather consider knowledge as something that can only be realized cooperatively by two or more individuals. It is this idea of a cooperative epistemology, which PET seeks to expand. ${ }^{27}$

The alternative view PET suggests with regard to the justification problem of expert testimony, is based in the prerequisite that a non-expert has a need to interact with the expert. To see this, consider that non-experts usually address experts for advice, because they expect them to be in an epistemic position that serves their own informational needs. For example,

\footnotetext{
${ }^{26}$ See footnote 3 .

${ }^{27}$ Note that what we call "cooperative epistemology" strongly differs from the program of a "communitarian epistemology" as promoted for example by Martin Kusch (Kusch 2002). Unlike Kusch we do not think that knowledge is a shared social status and that all aspects of knowledge are based in communal performative speech acts. What we share, however, is the idea that successful justification requires intersubjective agreement. It is mainly by virtue of this, that we consider knowledge a social phenomenon.
} 
patients usually address their doctors only when they need information about their medical condition. ${ }^{28}$ From the non-expert's perspective the expert is primarily an informant, who is in the position to serve his (subjectively) exclusive and esoteric informational needs. However, the non-expert will only acknowledge a purported expert as a good informant, if she is actually able to serve these informational needs. That is to say, the non-expert will question the informant's expert status, if the informant does not adequately respond to his questions. Take for example the typical epistemic relationship between a patient and a medical doctor. If the physician cannot provide the patient with an adequate diagnosis that explains the patient's suffering, her status as a medical expert becomes questionable in the eyes of this patient. ${ }^{29}$ This shows how one important condition for being an expert is being a good informant. ${ }^{30}$ Just as one can become an informant only through telling what one knows to information seeking persons, one can become a functional expert only through answering questions of persons seeking for information in one's domain of expertise. This implies that experts not only need to maintain justified true beliefs (i.e. knowledge) in their domain of expertise, they also need to have an interest to be approached as knowers in this specific domain. Without any possibility to testify what they believe they would not obtain their status as experts. This visibility and approachability as an expert is a necessary condition for being an expert We cannot think of experts as isolated from epistemically less well equipped non-experts or, vice versa, of non-experts as isolated from experts. In PET we draw on this insight.

Another trivial, but important aspect of PET is that it presupposes that knowledge depends on justification. ${ }^{31}$ As we saw above, this assumption is the reason, why knowledge from expert testimony is problematic in the first place. The case of expert testimony is characterized through the non-expert's lack of ability to acquire beliefs, which would count as justifying

\footnotetext{
${ }^{28} \mathrm{We}$ are well aware that in practice there are patients, who address doctors even though they are not in need of medical information. It should be obvious, however, that in such cases doctors are not actually addressed as medical experts.

${ }^{29}$ We do not intend to say that the expert status does solely depend on the judgement of a single non-expert. A medical doctor maintains her expert status through the acknowledgement of a larger community of non-experts and fellow experts respectively. We also grant that in practice there might be other, non-epistemic factors that might prevent a patient from questioning a doctor's expert status, such as a person's unconscious bias to generally accept the medical profession as authority.

${ }^{30}$ Of course, if the patient presses the issue further the doctor might still come up with explanations about why the requested information is uncertain or difficult to obtain; and maybe these explanations will help the doctor to restore her expert status in the eyes of her interrogator. We will get back to this epistemically important practice shortly.

${ }^{31}$ Some epistemologists have challenged this presupposition (e.g. Sartwell 1991; Hanfling 2000; Ernst 2002). However, they do not deny that having a justified true belief is often epistemically more desirable than just having a true belief. As we are not primarily concerned with knowledge as a concept in this article, granting only the later is sufficient for our argumentation.
} 
reasons for the beliefs he acquired through expert testimony. Even though the expert possesses justifying reasons for her belief, it is impossible for her - due to the non-expert's epistemic shortcomings - to transmit these reasons. The non-expert might possibly acknowledge that the expert has reasons for her belief that p. However, because he is a nonexpert, he will not be in the position to judge whether these reasons are sufficient to justify the belief, let alone to understand what would count as a relevant reason. A judgement about what would count as a relevant or even as a justifying reason would require what the non-expert, by definition, does not have: Expert knowledge.

Because of this, PET suggests that the non-expert's justifying reasons for his beliefs acquired from expert testimony, are generated through a cooperative process. This process consists in the expert's activity of dispelling the non-expert's doubts and produces justifying reasons on the side of the non-expert. The basic idea of PET is that a non-expert can acquire justifying reasons for a testified expert belief $\mathrm{p}$ through checking whether the expert has reasons for $\mathrm{p}$, which meet his doubts. ${ }^{32}$ Consider for example a patient, who after a regular medical checkup is told by his doctor that he suffers from a severe disease. Despite not having noticed any physical or psychical problems himself, this patient might nevertheless adopt the testimonial belief that he indeed suffers from the disease. In this case of "blind" trust in the doctor's opinion one would not say that the patient comes to "know" that he suffers from the disease, for he lacks reasons that justify this very belief. ${ }^{33}$ In a much more plausible scenario, however, the patient will probably hesitate to accept the seemingly unqualified diagnosis and ask the doctor for an explanation. If the doctor explains his reasons now in a way that is acceptable for the patient, the patient acquires a justifying reason for his belief in the testified diagnosis. Note, however, that this kind of justification generated through the non-expert's acceptance of the expert's explanation, does not and cannot require the non-expert to acquire the expert's justifying reasons. ${ }^{34}$ It is sufficient - and the only option, which maintains the epistemic difference between expert and non-expert - that the non-expert acquires some

\footnotetext{
${ }^{32}$ As will become clear on the following pages PET draws on a broad concept of "doubt". As a first approximation in PET a doubt includes all utterances and expressions, which imply a skeptical stance towards a proposition. This includes direct verbal articulations such as objection, negation or protest as well as more subtle verbal and non-verbal forms such as requests for clarification or refusals to belief the information.

${ }^{33}$ Those, who have opposite intuitions in this case, should note that it is not possible to say that the patient's trust in a doctor is an adequate justifying reason for his belief that he suffers from the disease. This is because blind trust relates at best to the doctor's general trustworthiness concerning medical issues, but not to the truth of a specific diagnosis.

${ }^{34}$ If a non-expert would in fact acquire the expert's justifying reasons he would turn into a potential expert herself. The non-expert is a non-expert precisely because he is not an expert with the capability of understanding these reasons and cannot - by virtue of this - function as a good informant for others in this domain of expertise.
} 
epistemically relevant reason that is acceptable for him and which functions as a justification within the context of the non-expert-community. If for instance the non-expert asked the doctor why she believes he suffers from this very disease, the doctor can dispel the nonexpert's doubt by pointing out that there are no other plausible explanations for the peculiar measures he sees in the patient's heamogram. If the patient is satisfied with this explanation, it generates a reason for him to acknowledge the doctor's status as a medical expert, which in turn provides him with a justifying reason for his belief in the doctor's testimony. Note once again that the patient does not need any medical background knowledge about measures in a heamogram for acquiring this justifying reason. For a satisfying explanation is one, which meets the non-expert's doubts and not one, which refers to measures which a non-expert is not in a position to doubt. In PET an explanation counts as epistemically acceptable, if it [1] dispels the non-expert's doubts and [2] in virtue of this generates a reason for the non-expert to assign his informant the expert status. In other words: If the doctor's explanation is sufficient for the patient to dispel his doubt in the belief that he indeed suffers from the diagnosed disease, then he is justified in confirming the expert status and - in virtue of this is justified in believing the doctor's testimony.

There are some respects in which our model resembles the conversation model of informed consent that has been proposed by Howard Brody for the context of primary care medicine (Brody 1989, 1993). ${ }^{35}$ On Brody's model informed consent is a mutual and participatory process and not a one-way disclosure of information through the physician. Brody's standard for transparency for example explicitly includes the condition that "the patient is allowed to ask questions suggested by the disclosure of the physician's reasoning, and those questions are answered to the patient's satisfaction" (Brody 1989, p.7). This is in line with PET as far as the answering of the patient's questions conveys reasons for the patient to believe the physician's testimony. PET, however, makes one step further insofar as the expert's performance is also important for establishing his epistemic authority. In PET the nonexpert's acceptance of the expert's efforts to dispel his doubts can be described as a confirmation of the expert status. In accepting an explanation as sufficient for adopting the testified belief the non-expert approves the expert's epistemic authority. In answering to a non-expert's doubts an expert demonstrates what it actually means to be an authority in his domain of expertise. To perform one's expertise is to be capable to answer to a large range of

\footnotetext{
${ }^{35}$ We thank an anonymous reviewer for pointing out this similarity.
} 
doubts about one's testified expert opinion. ${ }^{36}$ Hence, from the expert's perspective the act of testifying knowledge is successful, when it transmits a true belief and generates justifying reasons which move the non-expert to agree to believe in the expert's testimony. An agreement between non-expert and expert is reached, if both sides acknowledge that all relevant doubts have been dispelled and no further reasons exist for the non-expert to doubt the testified belief. This agreement is at the same time an expression for the justifying reasons the information seeking non-expert has acquired and for the acknowledgement of the informant's expert status. A successful performance of expertise, viz. the successful act of generating justifying reasons for the non-expert through dispelling his doubts, functions as a confirmation of the informant's expertise and provides in itself a reason for the non-expert to believe the expert.

Note that in PET it is enough that the non-expert accepts the expert's explanation as sufficient to dispel his doubts and agrees that in virtue of this a consensus with the expert has been reached. This does not imply, however, that the non-expert has the same reasons as the expert to hold the testified belief as true. What counts as a justifying reason is relative to the respective background beliefs of expert and non-expert. To dispel a doubt, all an expert needs to provide, is an explanation that is epistemically acceptable from the non-expert's perspective as a justifying reason to believe the testimony. To confirm the informant's expert status, all the non-expert is required to do is to signal that he agrees with the informant's testified belief. This mutual agreement constitutes the non-expert's knowledge and at the same time reaffirms the informant's expert status. ${ }^{37}$

In PET the non-expert's justification and knowledge and the informant's expert status are fluid. Both depend on the performance accepted by the non-expert as a sufficient reason to acknowledge the informant as expert and, hence, for holding the testified belief as true. ${ }^{38}$ Which performative act of expertise a non-expert can take as sufficient depends, however, on

\footnotetext{
${ }^{36}$ For our purposes we can leave open how large the range of doubts to be dispelled must be in order to become acknowledged as an expert. We assume however that in the process of becoming a scientific expert one comes across a comparatively great number of doubts and learns to dispel them.

${ }^{37}$ The reasons a non-expert acquires through PET are justifying if they function as sufficient reasons for belief in his lay community. To know that $\mathrm{p}$ a non-expert is not required to justify his believe that $\mathrm{p}$ against any doubts, which could possibly be raised against her belief. He is only required to justify this belief against the doubts of his fellow non-experts.

${ }^{38}$ It is important to note, that the acknowledgement is originating from the non-expert. PET can also take place in situations when the expert does not note that a non-expert's doubts are defied by her presentation of his expertise. E.g. if a non-expert reads an article written by an expert his doubts are quite often defied, because the expert anticipated them in her writing (same holds for videos or lectures etc.). In the writing of expert literature it is quite common to think about doubts a targeted audience is likely to have and to dispel them in advance. This is, by the way, what we do from chapter 5 onwards.
} 
the doubts he has raised. The patient in the above example might learn that his doctor's argument is taken as evidence for a different disease by others, e.g. his fellow non-experts, and he might take this as a defeater for his justification to believe the doctor's testimony. When the correct diagnosis becomes uncertain, there arise new informational needs on the patient's side. As a consequence justification for his belief can get lost and with this loss also his knowledge can disappear. The doctor can only meet these new informational needs (that are spelled out as doubts by the patient) by performing her expertise anew, viz. by presenting a new argument that speaks in favor of her initial diagnosis or defeats the new doubts.

\section{$4 \quad$ PET and the concept of justification}

This practical aspect has consequences for the concept of justification we use in PET. We take someone to be justified in believing a certain proposition, if he is able to dispel doubts raised against his view through relevant reasons. Therefore, we conceive of justification as a gradual property. We conceive of good informants as experts, because they are able to dispel a large number of doubts raised against their views; and we conceive of good informants as nonexperts, because they are less able to do so. This means that experts are gradually more justified in believing, what they believe than non-experts.

One might however wonder, whether such a purely performative understanding of justification is adequate to produce testimonial knowledge for non-experts. For if the expert would dispel the non-expert's doubt by making use of epistemically irrelevant arguments for instance by appealing to his social status or by trying to appear more trustworthy to the non-expert ${ }^{39}$ - these arguments should not count as a justification for the non-expert. If an expert successfully dispels a non-expert's doubt about a proposition $\mathrm{p}$ by simply appealing to power or authority, the success alone should not generate a justificatory reason for the nonexpert to believe $\mathrm{p}$. Being justified - or so it seems - requires believing that $\mathrm{p}$ not simply for some reason generated through the interaction of expert and non-expert, but for the epistemically relevant reasons.

We encounter this objection against the notion of justification as a practical ability by arguing that what counts as a justificatory reason is relative to the community in which a belief is

\footnotetext{
${ }^{39}$ One can easily think of properties that are taken as social indicators for expertise without being reliable. A white coat, a healthy appearance, and an empathic attitude towards their patients can help medical doctors to appear trustworthy, but are far from being reliable indicators of their medical knowledge and skill. Misinterpreting such properties as indicators for expertise is an eminent source of epistemic injustice (Fricker 2010).
} 
asserted. Hence, if a non-expert agrees with the expert to hold $\mathrm{p}$ as true because the expert has dispelled the non-expert's doubt by simply pointing out that she is an expert and knows better, we indeed consider the non-expert as justified to belief (and hence to know) p. However the community in which this non-expert would be accepted as being justified to belief (and hence to know) p, would probably not cover skeptics or other comparatively less credulous persons. An expert instead can be accepted as someone being justified to belief (and hence to know) p in a much wider community, simply because he is able to dispel more doubts raised against $\mathrm{p}$ by pointing to different justifying reasons in different communities. Note that it is not simply the size of the community in which a belief is assertable that defines the epistemic relevance of a justification but the asserting person's performance in dispelling the raised doubts. For the community which accepts the simple appeal to authority as justification can be quite large in some cases, whereas a community which accepts a reason requiring a background of esoteric expert knowledge can be quite small. Other than the non-expert the expert can dispel doubts raised by different communities - lay-communities and expert-communities - and this is not only what makes him an expert but also what lends epistemic relevance and credibility to his performance.

\section{Doubts about knowledge through performative justification}

Up to this point we laid out the epistemological problem of knowledge-acquisition from expert testimony and put forward an account to solve this problem. But as we want this solution to be accepted, we will concentrate on its justification in the following sections. Within the PET framework the demand to justify our account seems troubling, because this is obviously a written text and hence offers our readers no chance to directly articulate their doubts. However, we took some guesses, which doubts might bother our readers - at least the philosophers among them - when they consider if PET is a convincing solution.

First we want to refute the possible objection that the concept of knowledge underlying PET sets for epistemic relativism. This will be done in the reminder of this chapter [5]. Second, we need to address the worry that a PET justification cannot satisfy the enquiring non-expert's interest in justification. Moreover, we also consider the assumption that PET leads to far too much scepticism about expert knowledge for being convincing [6]. Third we will address the objection that the externalism about justification will bring the same results - justified true beliefs - for the non-expert but with far less resources to be invested [7]. 
We claimed that PET is capable to explain how the knowledge-acquisition from an expert testifier can succeed without the non-expert's trust. One may, however, object that PET is flawed in its current explanation, because it conceives of "knowledge" as relative to a community of knowers. PET demands that knowledge is constituted on the side of the nonexpert through agreement with the expert that all doubts have been dispelled. However, there are many things that can be produced by agreement in the right circumstances like marriages, laws, money, etc. but knowledge seems to be different in this regard. It is a deeply rooted intuition that knowledge needs more than mere acceptance by a community. It seems that to have knowledge that $\mathrm{p}, \mathrm{p}$ must be true and truth cannot be produced by agreement. ${ }^{40}$ Obviously, people can agree about many different things, but if these things are not the case, their acceptance does not render them true. ${ }^{41}$ By contrast, for the transmission of knowledge about $\mathrm{p}$ to be possible, it is necessary that $\mathrm{p}$ is true; and $\mathrm{p}$ being true is determined by the world, not by agreement. ${ }^{42}$ The same holds for believing that $\mathrm{p}$, because "believing that $\mathrm{p}$ " in the case of testimony needs to be thought of as "holding $\mathrm{p}$ as true". For the successful transmission of knowledge by testimony, it is necessary that both, expert and non-expert, believe that $\mathrm{p}$. But their believing that $\mathrm{p}$ should not be based on mutual practical interests alone. If one sticks to the standard definition of knowledge as a justified true belief and asks which part of these ternary conditions of knowledge can be produced by mutual agreement, one will see that only the justification condition is suitable to be satisfied by mutual agreement. $^{43}$

\footnotetext{
${ }^{40}$ The debate about the nature of truth is far from being resolved, but whatever will turn out to be the right conception of truth (if there is any), our account of expert testimony will be compatible with it. All we need from a theory of truth is the claim that truth needs to be independent from the specific people, who mutually agree. If this independence from the concrete consensus is spelled out in terms of idealized consensus (consensus theories), general warranted assertability (pluralism / pragmatism) or the world (correspondence theories) can be left open for our account.

${ }^{41}$ The same notion holds for verficationist or relativistic accounts conceptualising truth as kind of warranted assertability (c.f. McDowell 1976; Dummett 1978; Kusch 2002). Even if truth is best to be conceptualised as warranted assertability, all we need to claim is that the community needs to be bigger than just the expert and the non-expert discussing whether $\mathrm{p}$ is true. Consensus theories of truth (cf. Habermas 1973; Apel 1988) would argue as well that the discussion of a non-expert with an expert is too far away from consensus under ideal circumstances to account for the production of truths in this kind of discourse.

${ }^{42}$ This does not set us for a realist theory of truth. We can operate with a quite humble concept of "world" here by just stating that what makes a belief true is not the outcome of the specific deliberation between expert and non-expert, but something that cannot be settled by this deliberation alone, but is determined by something that is not up for discussion in a specific case of expert testimony.

${ }^{43}$ We need to leave the prominent doubts posed in the Gettier discussion about whether a true justified belief is knowledge (cf. Gettier 1963) and the challenge if we are capable of dispelling the doubt posed by the radical sceptical hypothesis (see e.g. Greco 2007) for another paper. But we are quite confident that this account has the resources to deal with these problems (See Hanfling 2000, Ernst 2002).
} 
First, consider truth: The truth of a belief's content is not liable to mutual agreement. Hence, the aim of expert testimony is not the production of truth, but the production of knowledge. Likewise truth is something scientists search for, but it is nothing they produce (and least of all through discussing their ideas with non-experts). It is necessary for a person for being considered an expert concerning $\mathrm{p}$ to have the true belief, that $\mathrm{p}$ prior to the dispelling of the non-expert's doubts. ${ }^{44}$

Next, consider belief: Strictly speaking a belief cannot be a result of mutual agreement. It is not necessary for a belief that someone else agrees with the holder of the belief on the belief's content; but it is a necessary condition that the holder believes that the content of his belief is true. ${ }^{45}$ Nevertheless, mutual agreement about $\mathrm{p}$ commonly supports the acquisition of the belief that $\mathrm{p}$. It is more likely that a person $\mathrm{S}$ adopts a belief widely held in her community than that she adopts this belief if it was not held or even rejected in her community. This supporting function of mutual agreement is commonly increased for the non-experts, if the mutual agreement happens to be agreement with an expert. Hence, neither truth nor beliefs solely depend on mutual agreement. But the aspect of justification - and this is central to PET - is to be analysed as a performative act of putting forward doubts and reasons to dispel them between the expert and non-expert. Only if there are no doubts about whether $\mathrm{p}$ is a fact for the expert or the non-expert, $\mathrm{p}$ is justified in the community consisting of these two parties. ${ }^{46}$

Keeping this in mind it is crucial to say more about the possibility of reason-production via PET and about which kind of interests have to be satisfied in order to allow for conceptualizing justification as a kind of declarative act that transforms a testified belief into knowledge for the non-expert.

\section{Knowledge and belief interests}

\footnotetext{
${ }^{44}$ Neither the testifier that tells falsehoods nor the testifier that fails to believe what he testifies is to be considered an expert. An expert is supposed to know p before she testifies and to tell her belief to the non-expert. As an expert she does not come to know that $\mathrm{p}$ only while dispelling the non-expert's doubts. In ideal situations the non-expert's doubts are not considered to have a bearing on the expert's belief, that p. E.g. a physician is supposed to collect the information necessary for a diagnosis and to tell me what she believes about my condition only afterwards, and a geographer is supposed to know what's the capital of Madagascar before telling me etc.

${ }^{45}$ It is the topic of a far more controversial debate whether as human beings we are capable to decide to acquire a belief or not (c.f. Smith 2005; Hieronymi 2008b). We will not position ourselves regarding this question in this paper. All we claim is agreement that the acquisition of a belief does not necessarily depend on agreement from others.

${ }^{46}$ Usually the community is much wider; there is seldom a case of an isolated expert coming to believe that $p$ is true and an isolated non-expert asking this expert. But for our purpose stick to the simplified picture of a knowledge community of one expert and one non-expert.
} 
What interests lead a person to ask an expert for information? Following Oswald Hanfling (Hanfling 2000, pp.96) there are mainly two situations, in which one asks for knowledge: enquiring situations and commenting situations. In the first case, one is interested in knowledge because one does not know whether $\mathrm{p}$ or not and wants to find out if one's interlocutor has a true belief about $\mathrm{p}$. In this situation, one is interested in someone who can be a good informant for $\mathrm{p}$. In the second case, one is interested if someone has a (true) belief of the same content. The situation of a non-expert asking for expert testimony is an enquiry situation. The non-expert is not in the position to know whether $\mathrm{p}$, the reason he addresses the expert is his belief that the expert has the true belief whether $\mathrm{p}$ and in virtue of this can answer the non-expert's question.

Given the context of the enquiry situation the most important non-expert expectation is to acquire true beliefs from expert testimony. If I ask my physician about my medical condition, I expect that her diagnosis is true and that she is telling me a fact about my medical condition. The main aim of a non-expert asking for expert testimony is to get true information without having to invest the resources to find out by himself; viz. by profiting from the division of epistemic labour. The second interest of a non-expert is to acquire beliefs he can assert within a wide community. For a belief being assertable within a community the members of this community have to view the asserting person as a good informant with regard to the asserted belief. As we are going to show, it is this second interest that marks an enquiry as a search for knowledge. For an acquired belief to be knowledge the community in which it can be asserted should be as wide as possible. And assertability in a wide community requires a non-expert to be able to give reasons for holding the acquired belief. PET is capable of giving an account how both these interests can be satisfied by expert testimony without relying on the nonexpert's pragmatic or moral reasons for trusting in the expert.

Considering the first interest one needs an explanation how a PET justification supports the non-expert in recognizing an expert as a good informant. For successfully recognizing someone as such at least two conditions have to be fulfilled. First, the belief testified by the expert must actually be true. In cases of testimony between epistemic peers the justification of the testifier is supposed to have a "truth guiding" function (Foley 1987, p.155; BonJour 1985, p.7) ensuring the knowledge-ascriber that the testified piece of information is true (given the 
total evidence). ${ }^{47}$ Second, the expert must be sincere when she testifies. In the case of testimony between epistemic peers the testifier's sincerity is secured by the enquirer's assessment of the testifier's justification in terms of coherence and overall credibility (Welbourne 1993; Kusch 2002). In the case of expert testimony, instead, it is hardly assessable for the non-expert whether the expert is credible and if her beliefs are coherent. Credibility and coherence are common assumptions if one considers someone an expert with regard to p. But these assumptions (up to this point) could only be explained by one's trust in the approached expert.

However, the picture of justification leading to trust as a proposed solution to the problem of expert testimony abstracts too much from the contextually embedded practice of justification. Stating that a justification for $\mathrm{p}$ has to be present in the testifier and to be given to the enquirer in a testimony situation conceives of the actual practice of question and answer as a generalised practice in which a testifier has ruled out all possible doubts before he is even asked to transmit his justification to the enquirer. However, taking a closer look on how the need for justification in non-expert-expert interactions arises in the more contextualised picture we offer in PET reveals that the need for a justification in enquiry situations arises only, if one cannot tell if one's counterpart is a good informant or just claims to be one. It is only in these situations, in which one has doubts whether $\mathrm{p}$ is true or not, that one demands justification. PET recognizes this as it takes doubts to be really articulated as a necessary condition for knowledge-acquisition from testimony. Thus, PET requires that the non-expert is indecisive whether the expert is a good informant or not before the process of reasonproduction can kick in.

This necessity for articulating doubts needs further explanation: What kind of non-expertdoubt is relevant in PET? For reasons already mentioned above, pointing out the defeating conditions of an expert's testimony for doubt to be relevant would not only bring PET dangerously close to non-reductionists' explanations but would also be an impossible requirement. What kind of doubt could a non-expert think of to defeat the theory of a high energy physicist? The non-reductionist description of relevant doubts catches the way that posing doubts and dismissing them works between epistemic peers, but it is unsuitable to constrain the doubts a non-expert can articulate in the case of expert testimony. If the expert

\footnotetext{
${ }^{47}$ Since it is of no bearing significance for our proposal to define who counts as an epistemic peer, we leave this question open. For this point an epistemic peer only needs to be a person capable of understanding the justification of the testifier.
} 
could dismiss doubts simply by asking why she should consider them relevant, the information asymmetry between expert and non-expert would prevent the non-expert from casting any doubt. Therefore, in PET there needs to be no mutual agreement for a doubt being relevant: What makes a doubt relevant is the non-expert thinking of his or her doubt as relevant.

If we grant this, however, the non-expert wouldn't need to put forward reasons for the doubts he articulates, and so the asymmetry between non-expert and expert seems to reverse: If it is very easy to cast doubts and very hard to dispel them, how can there be such a wide dependence on expert testimony? Obviously there must be at least some constraints on the way non-experts are to doubt and experts are to dispel doubts.

First of all, there are pragmatic reasons constraining the doubts of a non-expert. As we already pointed out, expert testimony depends on mutual interests of expert and non-expert and on the non-expert having an interest in getting to know whether $\mathrm{p}$. Of course one could imagine doubts, which are basically undefiable for an expert ${ }^{48}$. But this kind of sceptical inquiry is usually quite seldom in the case of non-experts. Casting undefiable doubts cannot be in the non-expert's interest, because it would mark all experts as bad informants for him and would thus make the division of epistemic labour impossible. Moreover, casting undefiable doubts wouldn't serve the non-expert's interest in a wide assertability for p either. As we pointed out one non-expert-interest was to acquire additional justifications for a true belief which could be used to dispel the doubts raised in the community of fellow non-experts and would make his belief more widely assertable. To achieve this goal a non-expert needs to put forward those doubts he expects to be casted by his community. But within many epistemic communities the unqualified doubt "I do not believe p" is not always reasonable. In communities of epistemic peers it is a widely held practice that doubts need to be shown as relevant; e.g. by pointing out the defeating conditions of a belief. The non-expert who wants to acquire reasons for asserting $\mathrm{p}$ within his community would therefore be well advised to cast doubts which could also be accepted in his epistemic community. Note that we do not consider these pragmatic arguments as decisive. A non-expert can always claim that he will not accept the expert's claim without being necessarily irrational or inconsistent. But the price he needs to pay in such a case is high: For then he will not consistently be able to resort on this kind of expertise to acquire information. One can, for example, pose the undefeatable doubt that all medical

\footnotetext{
${ }^{48}$ Especially in philosophy the cases of sceptical hypothesis are prominent (see Putnam 1982; Descartes 1641).
} 
experts are only vaccinating, because the pharmaceutical industry has indoctrinated them. But this doubt also rules out one's doctor prescribing any product from said pharmaceutical industry (including antibiotics, painkillers etc.). So, doubting on such a big scale also dries a source of information on a big scale. A non-expert cannot consistently have doubts concerning a whole field of expertise (e.g. pharmaceutical descriptions) but still rely on experts in this field, if it fits his needs.

One might, however, still object that this requirement of belief-consistency would be cognitively overstraining for non-experts. Who is ever fully consistent in their beliefs? The requirement of belief-consistency as it is understood in PET, however, only demands that the non-expert doesn't want to be wittingly inconsistent (cf. Harman 1986, p.56). Note, that in PET, inconsistencies have to be revealed by the expert, but needn't be known by the nonexpert in advance. The expert can do justice to this demand by either showing the non-expert that the information in question is consistent with the relevant beliefs the non-expert already has or by showing how rejecting specific expert testimony would result in inconsistent beliefs on the side of the non-expert. For example, the physician diagnosing an inflammation in my knee can dispel my doubt that it might as well be a strain by showing me how my beliefs that my knee hurts and pus is coming out of it are inconsistent with my belief that these symptoms do not indicate an inflammation.

But still a more general doubt could be raised against PET. By conceptualising "being justified" through the absence of doubts, PET seems to replace the explanation of how someone can be justified by the much weaker explanation of what it means to have no doubts. This problem can be spelled out by indicating that the account of justifications at work in PET only explains how a non-expert can be justified to belief $\mathrm{p}$ from expert testimony but not how a belief $\mathrm{p}$ is justified through expert testimony (Faulkner 2011, p.15). However, PET can encounter this objection by appealing to the argument that a person not doubting the expert's testimony can (usually) acquire only true beliefs, but not knowledge. A non-expert doubting the expert's testimony will acquire reasons he can use to dispel the same doubts when he confronts them in his community. Therefore this non-expert is much better off when he needs to defend his true belief against doubts; and it is this capacity, which (by and large) justifies his belief. Hence, it is not the case in PET that a non-expert deliberating with the expert just acquires excuses for believing $\mathrm{p}$; excuses, which he could utter even if $\mathrm{p}$ would be wrong. Instead the deliberation with the expert produces actual reasons he can use for both, defending his belief that $\mathrm{p}$ and arguing for $\mathrm{p}$ being a fact. In this sense the non-expert does not only 
acquire a reason for believing $\mathrm{p}$, but $\mathrm{p}$ is also justified for the non-expert, because there is no better way to justify $\mathrm{p}$ in this situation. For an example consider I asked an astrophysicist if Pluto was a planet and accepted her answer "no" without any questioning. Then I would acquire a true belief, but without further reasons I would not be capable of dispelling any doubts against it. I simply lack reasons for my belief that Pluto is not a planet. This lack of reasons for my true belief from expert testimony would render me a good informant regarding $\mathrm{p}$ only for those members of a community, who do not doubt $\mathrm{p}$ or trust the expert anyway. With a PET justification for $\mathrm{p}$, however, I can be acknowledged as a good informant also by those members of a community, who doubt for reasons similar to those I had before I acquired my belief from expert testimony. With a successful PET justification for $\mathrm{p}$ the community in which a non-expert can assert $\mathrm{p}$ is extended by members that have similar doubts as those already dispelled through PET. In PET in order to dispel the non-expert's doubts the expert identifies the beliefs responsible for the doubts and shows how they lead to inconsistencies in the non-expert's belief-system. After PET these steps can be repeated by the non-expert when he is confronted with the same doubts. Furthermore, doubts articulated by members of a community, in which doubts different than those dispelled through PET are present, won't force a non-expert to give up his PET belief as long as these doubts do not also affect the justifying reasons he acquired through PET. Therefore, a belief justified through PET tends to be more stable and more assertable than a mere true belief. PET conveys reasons to the nonexpert, which allow him to oppose doubts about PET-justified beliefs. This way PET is beneficial to satisfying the second interest of the non-expert.

This advantage of PET raises the question if the reproducibility of a PET justification is a necessary condition for getting a justified belief via PET. This would, however, be rather odd as it would require a clear distinction between reasons received by a non-expert via PET in order to defy doubts and reasons a non-expert acquires on his own. Furthermore, this would render the status of functional expertise dependent on the non-expert's capabilities to reproduce the experts reasoning instead of rendering them dependent on the expert's capabilities. It is necessary to acknowledge, that reproducibility is not necessary for the success of a PET justification. A PET justification is successful if all doubts of the non-expert are dispelled. With a PET justification it is likely that the non-expert obtains reproducible reasons to dispel doubts similar to his own but this advantage is not a necessary result of a successful PET justification. 
Another advantage of the account of justification at work in PET is that it also addresses the widely held intuition that a justification needs to have a "truth guiding function" (BonJour 1985, p.7; Steglich-Petersen 2013, p.204). The practice of giving and dispelling doubts allows for explaining how the justification provided by expert-non-expert-deliberation fulfils a weak truth guiding function (or rather a "reveal falsehood function"). If the testified expert belief $\mathrm{p}$ is false, this falseness should function as a constant generator of doubts in the non-expert or in the non-expert-community, which cannot be coherently dispelled altogether. ${ }^{49}$ Likewise, the truth of $\mathrm{p}$ should function as a constant generator of reasons to dispel doubts. However, p's falsehood is the stronger part in this model, because the production of doubts needs fewer resources and is usually more accessible for those seeking knowledge than the dispelling function of p's truth.

This is even more obvious, considering the fact that a truth guiding function alone cannot guarantee the truth of the non-expert's belief, because it cannot rule out the sceptical scenario of a sophisticated lying expert defying all the non-expert's doubts through rhetorical tricks. In this scenario the non-expert would consider his belief justified even if he was actually deceived by the expert's rhetoric. However, in PET there would still be a falsehood guiding function in this kind of deceptive justification, because the doubts a non-expert will be confronted with in his epistemic community wouldn't be defyable through the expert's rhetorical tricks alone. The non-expert wouldn't acquire any convincingly assertable reasons from the rhetorical trickster and - lacking the evil expert's rhetorical talent - wouldn't be capable to defy the doubts of his epistemic community. ${ }^{50}$ The reasons the evil expert will produce for the non-expert are, hence, dysfunctional with respect to the doubts that the nonexpert will find in his own epistemic community. As the persuasive power of this deceptive PET justification doesn't originate in the connection of the non-expert's beliefs but in the non-retraceable rhetorical ability of the expert, such a "fake-reason" will not produce widely assertable non-expert justifications.

Hence, PET gives the non-expert the rational resources for evaluating whether to accept or to reject the information given by an expert. The non-expert also acquires the resources to rationally evaluate whether the expert is a good informant concerning $\mathrm{p}$ (or the domain of

\footnotetext{
${ }^{49}$ Note that this does not imply that persistent disagreement between expert and non-expert is a reliable indicator for the falsehood of the expert's belief. In many cases of persistent disagreement experts and non-experts simply talk past each other, because they do not even have a genuine interest in knowledge-exchange.

${ }^{50}$ There would still be a realistic chance of an evil expert being undetected, if she would be capable to convince the whole non-expert community by her rhetoric tricks (e.g. by mass media communication).
} 
knowledge of $\mathrm{p}$ ). In the process of articulating doubts, the non-expert checks whether the expert's claim about $\mathrm{p}$ is coherent with other relevant beliefs of her own. ${ }^{51}$ And by casting the doubts and by assessing the way the expert dispels them the non-expert becomes able to evaluate the expert's credibility. The expert can only dispel the non-expert's doubts, if she uses evidence and reason understandable for the non-expert. In doing so she produces reasons for the non-expert for attributing the required credibility and the status of being an expert concerning $\mathrm{p}$ to her. Through PET the non-expert is also enabled to evaluate the expert's honesty. This is because in order to dispel doubts the expert needs to produce a longer line of arguments, which the non-expert is capable to check against his evidence for $\mathrm{p}$ or against other experts' opinions about $\mathrm{p}$ etc. In this model, justification is not a one-time act rendering a belief justified, but rather an ongoing process located in the deliberation between expert and non-expert. The reasons for believing that $\mathrm{p}$ for both, expert and non-expert, are therefore located in their mutual interest in knowing that $\mathrm{p}$ and in the doubts that already have been dispelled by PET. Thereby PET is beneficial for satisfying both kinds of belief interests the non-expert has in expert testimony, but without claiming that pragmatically or morally trusting the expert is inevitable.

\section{Externalist accounts of justification - An alternative to PET?}

Is the PET account of belief justification the only opportunity left to solve the problem of expert testimony? ${ }^{52}$ One might still think that not, because it seems that the problem of epistemic trust in expert testimony only arises for internalist accounts of justification. Only this kind of justification requires the subject to know her reasons for believing p (Burge 1993, p.459). But why should one approve of the internalist picture of justification offered by PET at all, if internalist accounts of justification turn out to be that complicated ${ }^{53}$ Reliabilist accounts of justification for example argue that a belief is justified if the belief was acquired in a reliable way or if the method used for belief acquisition was reliable. It does not matter for the reliabilist whether the subject consciously applies a method or whether the belief

\footnotetext{
${ }^{51}$ Relevant beliefs are all non-expert's beliefs contradicting the expert's claim.

${ }^{52}$ Note that we do not intend to exclude other possible ways of justifying a belief (e.g. collecting evidence for $\mathrm{p}$ ). All we want to point out is that all the accounts we discussed so far face all the considered problems when it comes to expert testimony.

${ }^{53}$ Expert testimony is quite common, but still a quite special source of justification. It would not be a defeater for externalist accounts of justification to say that in normal circumstances we (may be) searching for an internalist justification. However, because of our dependence on and the extraordinary circumstances of expert testimony, we are relying on a way of justification as proposed by externalist theories of justification.
} 
comes about in ways the subject is unaware of. It seems as if these accounts can explain how one can be justified without engaging in deliberative processes and still account for the nonexpert's interests in knowledge from expert testimony.

Admittedly, asking an expert for her beliefs about a subject is most of the time a quite reliable method to acquire true beliefs and might very often also satisfy the non-expert's interest for true beliefs. One might fear, however, that this property of reliabilism still wouldn't resolve the problem that the non-expert is not capable of deciding whether the expert tells the truth or errs (or is insincere), but reliabilists usually do not hesitate to transfer this function of the justification to the expert-domain (Goldman 2001). Moreover, reliabilism can also offer a satisfying answer for the second non-expert interest: the acquisition of widely assertable beliefs. "My expert (doctor, physicist etc.) told me so" seems to provide an extensive assertability in the community of people trusting my expert. Depending on the specific subject matter, trust in experts is still widespread and in most cases the community in which a nonexpert could assert $\mathrm{p}$ without a PET justification would still be quite significant. And what is more: Depending on the doubts a non-expert actually casts in a PET process the gain of assertability could be fairly marginal compared to the investment of resources necessary for a PET justification. So why bother with the spelling and dispelling of doubts, if one could just explain how the non-expert's belief that $\mathrm{p}$ is justified by referring to the reliability of her method for true belief-acquisition?

There is, however, one specific function of justification in expert testimony that reliabilism can't account for. It is the function of forming a community of knowers with the non-expert and the expert as its members, the importance of which we stressed in the first part of this paper. This function among others is fulfilled in PET; and only in virtue of this function PET allows explaining the rational acknowledgement of experts through non-experts.

Up to this point, we almost ignored the expert's interests. In contrast to the non-expert, the expert is not in an enquiring situation, she already knows the information she testifies. Hence, the acquisition of (reliable) true beliefs cannot be the expert's interest in engaging in testimonial exchanges with non-experts. Instead, the expert is interested in the recognition as a knower by a community and most of the time this community also has to include nonexperts. What reliabilism cannot account for is hence [1] that justified beliefs tend to be more 
stable than beliefs based solely on trust ${ }^{54}$ and [2] that the status of being an expert for $p$ depends primarily on the recognition by others as someone having true beliefs and of being able (in virtue of this) to justify one's belief for others. In the act of mutual recognition as a knower, the expert ensures that the non-expert views the expert not only as some good informant concerning $\mathrm{p}$, but as an expert concerning $\mathrm{p}$. Hence, as PET has it the social status of being an expert is closely connected to the status of being justified. A good informant can be anybody, who has the right belief concerning $\mathrm{p}$. But not every good informant is an expert. The status of being an expert exceeds the status of being a good informant among other things through the recognition as someone, who has not only true beliefs but is also capable of dispelling other's doubts or to convince them about the truth her belief. ${ }^{55}$ An expert in this sense is a justified good informant; and as the status of being an expert is ascribed for being justified in believing, the expert's justification has to be understandable for the person ascribing this status. Therefore, a crucial and beneficial function of PET is that it produces understandable justifications, which allow the non-expert to rationally declare a person an expert. Reliabilism can't account for such a strategy for flagging experts, and, hence, denies that the non-expert knows her own justifying reasons.

\section{Concluding Remarks}

In this paper we outlined a new account to the justification problem of expert testimony called performative expert testimony (PET) and defended it against some of the seemingly most pressing objections. As PET rests on a joint deliberation of expert and non-expert we focused on the idea of generating justifying reasons for the non-expert through a process of casting and dispelling doubts. Having shown that accepting a relativist conception of justification yields a more adequate explanation of what is at stake in knowledge-acquisition from expert testimony than externalist or reductionist accounts, we suggest that PET should be further

\footnotetext{
${ }^{54}$ We acknowledge that this is not a necessary truth. Many beliefs we acquire without any justification especially if we are young are far more stable than specific pieces of knowledge we acquainted throughout our adulthood (cf. Hyman 2015). Nevertheless, this thesis holds at least for those beliefs we acquired from testimony.

${ }^{55}$ What it takes to be an expert can basically be answered in two ways. First, objective accounts conceive of experts as persons that have a high amount of esoteric true beliefs in a domain of expertise, second reputational accounts conceive of experts as persons acknowledged as experts by others. It is the reputational account we are focusing on in this paper. If the expert wasn't recognized as an expert by a non-expert, her testimony would not count as a case of expert testimony, because the non-expert wouldn't have approached this person as an expert in the first place. Again, this does not mean that a person with expertise in a domain of knowledge is not worthy of being recognized as an expert. But the authority that comes attached to expertise in most concepts of "expert" must in PET be earned through becoming visible as an expert. And this means that aspiring experts need to use of their expertise by addressing other person's epistemic needs.
} 
explored as a theoretical basis for future science communication. What we haven't revealed in this paper, however, is most of the theoretical work, which inspired us to sketch a theory of expert testimony based on a contextualised interpretation of justification in the first place. The considerations on the concept of knowledge we operationalized in this paper rest on the idea that an adequate ascription of knowledge can only be reached if [1] a person S's belief that $p$ is true and if [2] S's reasons for believing $p$ are agreed to be relevant in the communicative context, in which $\mathrm{S}$ utters $\mathrm{p}$. So whether $\mathrm{S}$ knows $\mathrm{p}$ depends among other things on $\mathrm{S}$ accepting to be declared as justified in believing p. It is especially this second requirement which PET tries to make plausible for the context of expert testimony. However, how this general idea may help, to address the long standing problems in the theory of knowledge such as Skepticism and the Gettier cases is a promising question for further epistemological explorations. 


\section{References}

Almassi, B. (2012). Climate Change, Epistemic Trust, and Expert Trustworthiness. Ethics and the Environment 17(2), 29-49. DOI: 10.2979/ethicsenviro.17.2.29.

Apel, K.-O. (1988). Diskurs und Verantwortung. Das Problem des Übergangs zur postkonventionellen Moral. Frankfurt am Main: Suhrkamp.

Baier, A. (1986). Trust and antitrust. Ethics 96(2), 231-260. DOI: 10.1086/292745.

BonJour, L. (1985). The structure of empirical knowledge. Cambridge, Mass: Harvard University Press.

Brewer, S. (2006). Scientific expert testimony and intellectual due process. In E. Selinger, E., R. P. Crease (Eds.): The Philosophy of Expertise. New York: Columbia University Press, 111-158.

Brody, H. (1989). Transparency: Informed consent in primary care. Hastings Center Report 19(5), 5-9. DOI: $10.2307 / 3562634$.

Brody, H. (1993). The Healer's Power. Reissue edition. New Haven: Yale University Press.

Burge, T. (1993): Content preservation. Philosophical Review 102(4), 457-488. DOI: 10.2307/1523046.

Chakrabarti, A., Matilal, B. K. (Eds.) (1994). Knowing from words. Western and Indian philosophical analysis of understanding and testimony. Dordrecht: Kluwer (Synthese Library, 230).

Coady, C. A. J. (1992). Testimony: A Philosophical Study. Oxford: Oxford University Press.

Coady, D. (2006). When Experts Disagree. Episteme 3(1-2), 68-79. DOI: 10.3366/epi.2006.3.1-2.68.

Collins, H. M.; Evans, R. (2007). Rethinking expertise. Chicago: University of Chicago Press.

Daukas, N. (2006). Epistemic Trust and Social Location. Episteme: A Journal of Social Epistemology 3(1-2), 109-124. DOI: 10.3366/epi.2006.3.1-2.109.

Descartes, R. (1641/2014): Meditationes de prima philosophia. (deutsch: Meditationen über die erste Philosophie). Stuttgart: Reclam.

Dormandy, K. (2017). Epistemic Authority. Preemption or Proper Basing? Erkenntnis 6 (4). DOI: 10.1007/s10670-017-9913-3.

Dummett, M. (1978): Truth and other enigmas. London: Duckworth.

Ernst, G. (2002). Das Problem des Wissens. Paderborn: Mentis.

Faulkner, P. (2007). On Telling and Trusting. Mind 116(464), 875-902. DOI: 10.1093/mind/fzm875.

Faulkner, P. (2011): Knowledge on Trust. Oxford: Oxford University Press.

Faulkner, P. (2014). The moral obligations of trust. Philosophical Explorations 17(3), 332-345. DOI: 10.1080/13869795.2014.942228.

Faulkner, P., Simpson, T. (Eds.) (2017): The Philosophy of Trust. Oxford: Oxford University Press.

Foley, R. (1987). The theory of epistemic rationality. Cambridge, Mass.: Harvard University Press.

Fricker, M. (2010). Epistemic injustice. Power and the ethics of knowing. Reprinted. Oxford: Oxford University Press.

Frost-Arnold, K. (2013). Moral Trust \& Scientific Collaboration. Studies in History and Philosophy of Science 44(3), 301-310. DOI: 10.1016/j.shpsa.2013.04.002.

Frost-Arnold, K. (2014). The cognitive attitude of rational trust. Synthese 191(9), 1957-1974. DOI: 10.1007/s11229-012-0151-6.

Gettier, E. L. (1963). Is Justified True Belief Knowledge? Analysis 23(6), 121-123.

Goldman, A. I. (1999). Knowledge in a social world. Oxford, New York: Clarendon Press.

Goldman, A. I. (2001). Experts. Which ones should you trust? Philosophy and Phenomenological Research 63(1), 85-110. DOI: 10.1111/j.1933-1592.2001.tb00093.x. 
Greco, J. (2007). Discrimination and testimonial knowledge. Episteme: A Journal of Social Epistemology 4(3), 335-351. DOI: 10.3366/E1742360007000123.

Guerrero, A. A. (2017). Living with Ignorance in a World of Experts. In R. Peels (Ed.): Perspectives on ignorance from moral and social philosophy. New York: Routledge Taylor \& Francis Group (Routledge studies in contemporary philosophy, 85), 156-183.

Habermas, J. (1973). Wahrheitstheorien. In H. Fahrenbach (Ed.): Wirklichkeit und Reflexion. Walter Schulz zum 60. Geburtstag. Pfullingen: Neske, 211-265.

Hanfling, O. (2000). Philosophy and ordinary language. The bent and genius of our tongue. London, New York: Routledge (Routledge studies in twentieth century philosophy).

Hardin, R. (2002). Trust and trustworthiness. New York: Russell Sage Foundation (The Russell Sage Foundation series on trust, volume 4).

Hardwig, J. (1985). Epistemic Dependence. Journal of Philosophy 82(7), 335-349.

Hardwig, J. (1991). The role of trust in knowledge. Journal of Philosophy 88(12), 693-708.

Harman, G. (1986). Change in view. Principles of reasoning. Cambridge, Mass.: MIT Press.

Hawley, K. (2014). Trust, Distrust and Commitment. Noûs 48(1), 1-20. DOI: 10.1111/nous.12000.

Hieronymi, P. (2008a): The reasons of trust. Australasian Journal of Philosophy (86)2, 213-236. DOI:

$10.1080 / 00048400801886496$

Hieronymi, P. (2008b). Responsibility for believing. Synthese 161(3), 357-373. DOI: 10.1007/s11229-006-9089$\mathrm{X}$.

Hinchman, E. (2005). Telling as inviting to trust. Philosophy and Phenomenological Research 70(3), 562-587. DOI: 10.1111/j.1933-1592.2005.tb00415.x.

Holton, R. (1994). Deciding to trust, coming to believe. Australasian Journal of Philosophy 72(1), 63-76. DOI: $10.1080 / 00048409412345881$

Hyman, J. (2015). Action, Knowledge, and Will. First edition. Oxford, New York: Oxford University Press.

Jäger, C. (2016). Epistemic Authority, Preemptive Reasons, and Understanding. Episteme: A Journal of Social Epistemology 13(2), 167-185. DOI: 10.1017/epi.2015.38.

Jones, K. (1996). Trust as an Affective Attitude. Ethics 107(1), 4-25. DOI: 10.1086/233694.

Kappel, K. (2014). Believing on trust. Synthese 191 (9), 2009-2028. DOI: 10.1007/s11229-013-0376-z.

Kusch, M. (2002). Knowledge by Agreement. The Programme of Communitarian Epistemology. Oxford, New York: Oxford University Press.

Lackey, J. (2008). Learning From Words. Testimony as a Source of Knowledge. Oxford: Oxford University Press.

Lackey, J. (2016). To Preempt or not to Preempt. Episteme: A Journal of Social Epistemology 13(4), 571-576. DOI: 10.1017/epi.2016.32.

Lahno, B. (2001). On the Emotional Character of Trust. Ethical Theory and Moral Practice 4(2), 171-189. DOI: 10.1023/A:1011425102875.

Lawlor, K. (2013). Assurance. An Austinian View of Knowledge and Knowledge Claims. Oxford: Oxford University Press.

Martini, C. (2014). Experts in science. A view from the trenches. Synthese 191(1), 3-15. DOI: 10.1007/s11229013-0321-1.

McDowell, J. (1976). Meaning, bivalence, and verificationism. In G. Evans (Ed.): Truth and meaning. Essays in semantics. Oxford: Clarendon Press, pp. 42-66.

McMyler, B. (2011). Testimony, trust, and authority. Oxford, New York: Oxford University Press.

Moran, R. (2005). Getting told and being believed. Philosophers' Imprint 5(5), 1-29.

Putnam, H. (1982). Reason, truth and history. Cambridge: Cambridge University Press. 
Sartwell, C. (1991). Knowledge is merely true belief. American Philosophical Quarterly 28(2), 157-165.

Smith, A. M. (2005). Responsibility for Attitudes. Activity and Passivity in Mental Life. Ethics 115(2), $236-271$. DOI: $10.1086 / 426957$.

Steglich-Petersen, A. (2013). Truth as the aim of epistemic justification. In T. Chan (Ed.): The aim of belief. Oxford: Oxford University Press, 204-226.

Welbourne, M. (1993). The community of knowledge. Aldershot: Gregg Revivals (Modern revivals in philosophy).

Wilholt, T. (2013). Epistemic Trust in Science. The British Journal for the Philosophy of Science 64(2), 233253. DOI: 10.1093/bjps/axs007.

Zagzebski, L. (2012): Epistemic authority. A theory of trust, authority, and autonomy in belief. Oxford: Oxford University Press. 